\title{
Developing a framework for evaluating robotic care devices in the introduction phase
}

\author{
Homma, Keiko; Yasuoka, Mika; Akutsu, Yasuko; Matsumoto, Yoshio
}

Published in:

ISR 2021 - 2021 IEEE International Conference on Intelligence and Safety for Robotics

DOI:

10.1109/ISR50024.2021.9419384

Publication date:

2021

Document Version

Peer reviewed version

Citation for published version (APA):

Homma, K., Yasuoka, M., Akutsu, Y., \& Matsumoto, Y. (2021). Developing a framework for evaluating robotic care devices in the introduction phase. In ISR 2021 - 2021 IEEE International Conference on Intelligence and Safety for Robotics (pp. 77-80). [9419384] IEEE. ISR 2021 - 2021 IEEE International Conference on Intelligence and Safety for Robotics https://doi.org/10.1109/ISR50024.2021.9419384

\section{General rights}

Copyright and moral rights for the publications made accessible in the public portal are retained by the authors and/or other copyright owners and it is a condition of accessing publications that users recognise and abide by the legal requirements associated with these rights.

- Users may download and print one copy of any publication from the public portal for the purpose of private study or research.

- You may not further distribute the material or use it for any profit-making activity or commercial gain.

- You may freely distribute the URL identifying the publication in the public portal.

Take down policy

If you believe that this document breaches copyright please contact rucforsk@kb.dk providing details, and we will remove access to the work immediately and investigate your claim. 


\title{
Developing a Framework for Evaluating Robotic Care Devices in the Introduction Phase
}

\author{
Keiko Homma, Member, IEEE, Mika Yasuoka, Yasuko Akutsu and Yoshio Matsumoto
}

\begin{abstract}
This paper describes the current evaluation frameworks for the development of robotic care devices, and compares these with an existing health technology assessment (HTA) framework that is used for decision making in healthcare. Finally, it considers how best to evaluate robotic care devices being introduced into care settings in Japan.
\end{abstract}

\section{INTRODUCTION}

In Japan, the introduction of robotic care devices into care settings is gradually progressing, but the devices have yet to be broadly used. A possible reason is the lack of proper evaluation in the introduction phase.

This paper describes the current evaluation frameworks for the development of robotic care devices in Japan, and compares these with an existing health technology assessment framework that is used for healthcare policy- and decisionmaking. Finally, it considers how best to evaluate robotic care devices being introduced into care settings in Japan.

\section{EVALUATION FRAMEWORKS FOR THE DEVELOPMENT OF ROBOTIC CARE DEVICES IN JAPAN}

Robotic care devices are care devices with improved usefulness and safety due to robotic technology, which aim to support the independent living of elderly people and reduce the burden on caregivers.

In FY2012, the Japanese Ministry of Economy, Trade and Industry (METI) and Ministry of Health, Labour and Welfare (MHLW) determined the "Priority Areas to which Robot Technology is to be Introduced in Nursing Care" [1]. Currently, there are 13 such areas, in 6 fields (Fig. 1).

Several evaluation criteria have been proposed for making decisions on whether to introduce robotic care devices or assistive robots into caregiving environments. However, since assistive robots have only recently come into use, there are, as yet, very few cases where the proposed evaluation criteria have been used in practice.

Several guidebooks on the development of robotic care devices have been published, with the following perspectives on evaluation.

Keiko Homma and Yoshio Matsumoto are with Assistive Robotics Research Team, Human Augmentation Research Center, the National Institute of Advanced Industrial Science and Technology (AIST), 6-2-3 Kashiwanoha, Kashiwa, Chiba 277-0882 Japan (e-mail: keiko.homma@aist.go.jp, yoshio.matsumoto@aist.go.jp).

Mika Yasuoka is with Sustainable Digitalization, Roskilde University, Universitetsvej 1 DK-4000 Roskilde, Denmark. (e-mail: mikaj@ ruc.dk).

Yasuko Akutsu is with MT Health Care Research Inc., 1-17-6 Uchikanda,Chiyoda-ku,Tokyo, Japan. (e-mail: yasukoakutsu@hcdr.co.jp).

\section{A. The Guidebook for Development of Robotic Devices for Nursing Care}

The Guidebook for Development of Robotic Devices for Nursing Care [2] was published as a result of the "Project to Promote the Development and Introduction of Robotic Devices for Nursing Care" (FY2013-2017), funded by METI and the Japan Agency for Medical Research and Development (AMED) [3]. Aimed primarily at developers of robotic care devices, the guidebook describes the developmental methodology employed in the development process proposed in the Project.

The guidebook defines the development process of robotic care devices in terms of the following six steps.

- Definition of the development concept

- Design of specifications based on the mechanical model

- Risk assessment

- Robot design and manufacturing

- Safety verification and validation

- Demonstration testing

Safety and usefulness are identified as the key concepts for evaluation. In the case of safety, a separate guidebook, the Safety Handbook for Development of Robotic Devices for Nursing Care [2], was published, with a special focus on ensuring the safety of the devices as machines. In the case of usefulness, the guidebook notes that the operator's working time and burden should be used as outcome measures, and that the "ICF model", which is presented in the "International Classification of Functioning, Disability and Health (ICF)" [4] should be used as a tool to evaluate the effects (including unintended effects) of the device on humans.

\section{B. The Guideline for Development and Introduction of Robotic Devices for Nursing Care}

In addition to the guidebooks described in the previous section, the Guideline for Development and Introduction of Robotic Devices for Nursing Care [2] focuses on how to utilize robotic care devices as a physical means of nursing care aiming at improvement in the elderly's quality of life.

It states that the effects of such devices on people should be evaluated at the three different levels of life functioning, based on the ICF model: elemental movement, activity, and participation. 


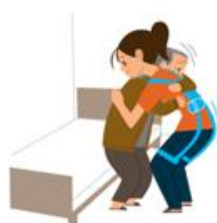

(a)

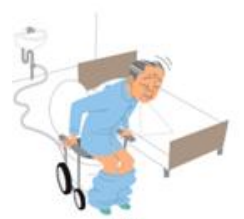

(f)

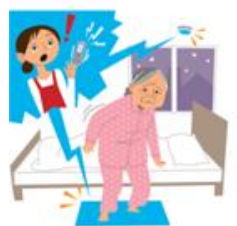

(j)

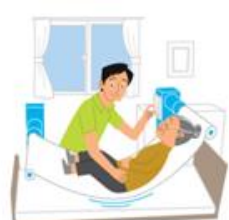

(b)

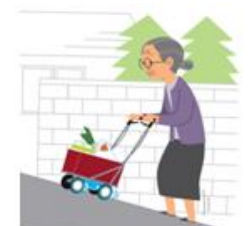

(c)

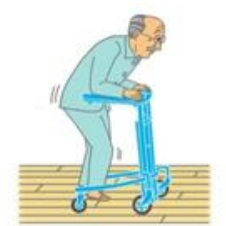

(d)

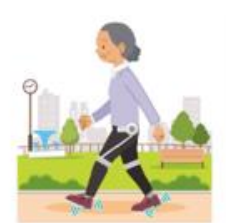

(e)

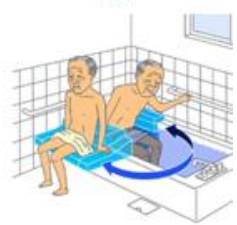

(i)

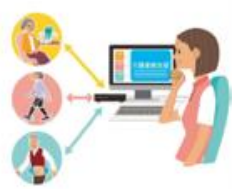

(m)

Figure 1. Figure 1. The priority areas to which robot technology is to be introduced in nursing care; (a) wearable transfer aids, (b) non-wearable transfer aids, (c) outdoor mobility aids, (d) indoor mobility aids, (e) wearable mobility aids, (f) toileting aids, (g) toileting anticipation aids, (h) toileting action aids, (i) bathing aids, (j) monitoring systems for nursing care homes, (k) monitoring systems for private homes, (l) communications, (m) care services support.

\section{The Guide to the Development of Assistive Devices and Nursing Care Robots}

In FY2013, the MHLW published the Guide to the Development of Assistive Devices and Nursing Care Robots, based on the knowledge obtained through the "Project for Practical Application of Assistive Devices and Nursing Care Robots" (FY 2011-2013) [5]. The purpose of this guide is to provide basic knowledge about the process of development of such devices, what to keep in mind at each stage of development, how to collect necessary information, and how to evaluate the development status for manufacturers who are going to engage in the development of nursing care robots.

In the guide, the introduction of robotic care and assistive devices involves the following stages.

- Developmental preparation

- Conceptual design/principle confirmation

- Development of prototype

- Operation check/action check

- Improvement of the prototype/confirmation of improvement in operation and function

- Development of commercial product

- Market launch

- Improvement of the product

- Continuous improvement

- Prevalence
Both in evaluations by nursing care experts during the preparation phase, and in evaluations by testers during the development phase, the robotic care devices and assistive devices are evaluated in terms of the following three aspects.

- Intended users

- Environmental suitability

- $\quad$ Expected effects

\section{THE HEALTH TECHNOLOGY ASSESSMENT FRAMEWORK}

In Europe and other countries, most assistive devices are categorized as medical devices. Therefore, evaluation methods for medical devices can, in principal, be applied to evaluations regarding the introduction of assistive devices.

Health technology assessment (HTA) is used as a multidimensional evaluation model for governments and other stakeholders to use as a basis for decision making regarding the introduction of medical procedures, drugs, medical devices, etc. In HTA-based evaluation, the safety, effectiveness, and affordability of the target technology are evaluated, as well as the impact on the respective organization, patients, and society, and the ethical and legal aspects of the technology.

Here we will focus on the HTA Core Model, a framework for conducting and sharing assessments, provided by the European Network for Health Technology Assessment (EUnetHTA), a Europe-wide network of HTA-related organizations [6].

In the HTA Core Model, evaluation is performed from 
seven perspectives called "domains".

- Health problem and current use of technology

- Description and technical characteristics of technology

- Safety

- Clinical effectiveness

- Costs and economic evaluation

- Ethical analysis

- Organizational aspects

- $\quad$ Patient and social aspects

- Legal aspects

The Safety domain, for example, describes the direct and indirect hazards of the technology to patients, staff, and the environment, and how to reduce the risk of harm. It consists of four subcategories called "topics": patient safety, occupational safety, environmental safety, and safety risk management.

In the Safety domain evaluation, quality-adjusted life years (QALYs) and disability-adjusted life years (DALYs) are used as outcome measures, which take into account patient life expectancy and quality of life, in addition to the frequency of adverse events, the relative risks and risk differences, and odds ratios.

The domains of the HTA Core Model are interrelated, with safety considerations, for example, also appearing in other domains than the Safety domain.

Since the implementation of a full version of HTA requires a significant amount of time and effort, the HTA Core Model for the Production of Rapid Relative Effectiveness Assessments is also provided by EUnetHTA. Other groups also offer simplified and more focused HTA tools, such as the Mini-HTA in the form of a checklist [7]; a model for assessment of telemedicine applications (MAST) [8]; Digi-HTA, specializing in the evaluation of digital medicine, including robotics and AI [9]; and Welfare Technology Assessment (VelfardsTeknologiVurdering or VTV) specializing in the evaluation of assistive devices [10].

In Japan, HTA is mainly used in the cost-benefit evaluation of pharmaceuticals and medical devices, with few attempts having been made to apply it to the evaluation of assistive devices in the introduction phase.

\section{DISCUSSION}

Both the Guidebook for Development of Robotic Devices for Nursing Care and the Guide to the Development of Assistive Devices and Nursing Care Robots primarily target manufacturers of robotic care devices, focus mainly on the evaluation of safety and usefulness, and make very little reference to cost evaluation. Further, their target is the development phases up to demonstration testing. Overall, they provide only limited information for deciding on the introduction of robotic care devices.
The Guideline for Development and Introduction of Robotic Devices for Nursing Care is for potential users of robotic care devices, targeting both the demonstration experiment phase and the practical installation phase. It describes the policy on how to utilize robotic care devices that have been decided to be introduced in care settings; however, it does not address how to evaluate for decision making regarding the introduction of such devices.

In Europe and other countries, the HTA framework has already been established. Though the primary objective of HTA is to provide information for decision making in developing healthcare policy, it can be extended to evaluate new technologies at healthcare institutions; and, among other things, the HTA framework includes technological, user-focused, organizational, and economical aspects. On the other hand, as aforementioned, the implementation of the full version of HTA requires much time and effort, and thus is not appropriate for the evaluation of robotic care devices, due to the rapid progress in robotics technology. A simplified framework is required for the evaluation of such devices.

Finally, the following differences may be observed between Japan and Europe in the positioning of assistive devices.

\section{A. Safety}

In many countries, including those of Europe, assistive devices are categorized as medical devices, and thus the manufacturing process follows the manufacturing procedures for medical devices (e.g., CE marking). In Japan, however, most assistive devices are regarded as non-medical devices and often manufactured as general products, which may lead to differences in efforts to secure product safety in the manufacturing process.

Further, in the case of Japan, premature assistive technologies are sometimes introduced in care settings, which may increase the risk for users. Therefore, safety evaluation must take into account the maturity of technology. For example, at the beginning of the evaluation, MAST, one of the HTA frameworks, has a question on product maturity, which reduces the risk of premature technologies being introduced to users. A similar item should be included in evaluation frameworks for robotic care devices.

\section{B. Costs}

In Denmark, for example, assistive devices are purchased by municipalities, and rented free of charge to those who, in the judgment of the healthcare professionals, are expected to have their lives improved through the use of the devices. Therefore, municipalities make the final decision on whether a new device is introduced or not, and are thereby motivated to maintain uniform criteria for making such decisions. In Japan, on the other hand, the long-term care insurance system limits the types of assistive devices covered by the insurance, and other devices are left to the open market, from which public nursing homes have very little motivation to procure them. The home-living elderly can buy or rent the equipment of their choice (to a certain extent), but little information is provided for them to make a decision on obtaining suitable devices. 
Given these differences, it is important to establish a multidimensional assessment framework for the evaluation of robotic care devices in the introduction phase, and the HTA framework is expected to provide the basis for this. However, the framework should be modified to enable effective evaluation of such rapidly evolving technology.

\section{SUMMARY}

This paper compared current evaluation frameworks for the development of robotic care devices in Japan, with an HTA framework, and discussed the best means of evaluating robotic care devices that may be introduced in care settings in Japan. The HTA framework is expected to provide a solid foundation for multidimensional assessment of such devices.

In future, we will attempt to develop a framework prototype.

\section{REFERENCES}

[1] Revision of the Priority Areas to Which Robot Technology is to be Introduced in Nursing Care,

https://www.meti.go.jp/english/press/2017/1012_002.html.

[2] Robotic Care Devices Portal,

http://robotcare.jp/en/outcomes/index.php?PHPSESSID=ebukev8rh31 6bmof5trmlm39ff.

[3] Project to Promote the Development and Introduction of Robotic Devices for Nursing Care,

https://www.amed.go.jp/en/program/list/02/01/005.html.

[4] International Classification of Functioning, Disability and Health (ICF), https://www.who.int/standards/classifications/international-classificati on-of-functioning-disability-and-health.

[5] Guide to the Development of Assistive Devices and Nursing Care Robots,

http://www.techno-aids.or.jp/research/robotebiki_mhlw_140922.pdf (In Japanese).

[6] HTA Core Model, https://eunethta.eu/hta-core-model.

[7] Introduction to mini-HTA,

https://www.sst.dk/ /media/47C62A769EBC4E80A153F986C5348F5 5.ashx.

[8] K. Kidholm, A.G. Ekeland, L.K. Jensen, J. Rasmussen, C.D. Pedersen, A. Bowes, S.A. Flottorp and M. Bech, "A Model for Assessment of Telemedicine Applications: MAST", International Journal of Technology Assessment in Health Care, vol. 28, no.1, pp.44-51, Jan. 2012.

[9] J. Haverinen, N. Keränen, P. Falkenbach, A. Maijala, T. Kolehmainen, and J. Reponen, "Digi-HTA: Health technology assessment framework for digital healthcare services", Finnish Journal of eHealth and eWelfare, vol. 11, no. 4, pp. 326-341, Nov. 2019.

[10] VTV - VelfærdsTeknologiVurdering, https://www.teknologisk.dk/ydelser/vtv-velfaerdsteknologivurdering/3 2944 ?cms.query=VTV (In Danish). 